\title{
QUEM TE VIU, QUEM TE VÊ: AS MUDANÇAS DO COMPOSTO MERCADOLÓGICO DO VAREJO DE SHOPPING CENTERS DA REGIÃO DO VALE DO ITAJAII/SC DURANTE A SUA EXISTÊNCIA
}

\author{
Look at you now! The retail marketing mix changing \\ in Itajai Vallery region/SC malls during their existence
}

Envio 19.10.08/ Aceite 26.04.09

\section{Ricardo Boeing da Silveira ${ }^{1}$ \\ Mônica Sinem²}

\begin{abstract}
Resumo
O crescimento do número de shopping centers no Brasil e o bom desempenho do varejo nos últimos meses demonstram a participação no mercado deste segmento e estimula o surgimento de pesquisas a respeito do tema. Para avaliar as mudanças do composto mercadológico do varejo de shoppings da região do Vale do Itajaí, em Santa Catarina, foram realizadas entrevistas semiestruturadas, sendo que participaram da investigação dois dos três estabelecimentos existentes na localidade citada, escolhidos pelo tempo de existência. A abordagem qualitativa foi utilizada com o intuito de se obter maior complexidade nas respostas e devido ao número reduzido da amostra existente. Para a análise das informações coletadas, usou-se a categorização simples, comparando-se os dados entre si e com a teoria estudada, para possibilitar a visualização das diferenças do mix de varejo entre os shoppings, com o passar do tempo e literatura sobre o tema. Percebeu-se, nos resultados, que o shopping localizado em Itajaí trabalha seu composto de varejo de modo similar desde a sua inauguração. Já o estabelecimento de Balneário Camboriú adaptou algumas de suas ações com o intuito de captar mais clientes e se preparar contra a concorrência. No final do trabalho, são expostas as limitações da pesquisa e sugestões para trabalhos futuros. Marketing.

Palavras-chave: Varejo, Composto Mercadológico, Shopping Center, Mudanças,

1Doutorando em Administração pela FGV/EAESP. Professor de cursos de graduação e pós-graduação na área de Marketing da Universidade do Vale do Itajaí (UNIVALI). E-mail: boeing@univali.br

${ }^{2}$ Especialista em Administração. E-mail: m.sinem@uol.com.br
\end{abstract}




\begin{abstract}
The growth of Brazilian malls and the good performance of retail in the last months demonstrates the participation in the market of this segment and stimulates research regarding the subject. To evaluate the changes of the retail marketing mix of malls in the Itajaí Valley, in Santa Catarina, interviews have been done, and two of the three existing establishments in the localtions participated of the inquiry, chosen for the existing time. The qualitative strategy was used with the intention of getting greater complexity in the answers and due to the reduced number of the existing population. For the analysis of the collected information, it was used simple interpretation, comparing the data between the two analyzed malls and with the studied theory to visualize the differences of retail marketing mix between them. It was noticed, in the results, that the mall located in the city of Itajai works its retail mix similar to when its opening. Yet the establishment in Balenário Camboriú adapted some of its actions intending to get more customers and to prepare itself against the competition. In the end of the paper the limitations and suggestions for future research are presented.
\end{abstract}

Keywords: Retail, Marketing Mix, Mall, Changing, Marketing.

\title{
1 Introdução
}

A disputa pelo consumidor em um ambiente instável e com entrada constante de novos concorrentes exige das empresas a implementação de ações mercadológicas sustentáveis e passíveis de adaptação. A evolução do setor de varejo, nos últimos oito anos, também representa oportunidades para aqueles que estão presentes neste cenário. Sendo assim, toda e qualquer estratégia que diferencie a empresa da concorrência é válida e necessária, e neste caso, uma maior atenção é dispensada ao composto mercadológico praticado no varejo.

A apresentação das lojas, as pessoas que nelas trabalham, os produtos comercializados, a disponibilização de produtos aos clientes, a forma como são promovidos e as suas políticas de preços correspondem às preocupações primordiais dos varejistas (BERMAN e EVANS, 2006; BERNARDINO et al., 2004; BALASUBRAMANIAN, 1998). Tais aspectos são considerados relevantes no mercado de varejo porque influenciam dois aspectos: a decisão dos clientes de onde e quando comprar e dos varejistas em onde, quando e como operar suas lojas (OPPEWAL e TIMMERMANS, 1997).

No presente contexto, os shopping centers representam um importante papel, tanto pela sua participação dentro do setor varejista, como pela gama de produtos e serviços oferecidos aos clientes (PRATT e PRATT, 1960; BERMAN e EVANS, 2006). A praticidade e o conforto que oferecem incrementaram o número de unidades existentes no Brasil, e sua preferência cresceu em quase todos os segmentos de mercado, diversificando as opções de compras e lazer disponíveis aos consumidores (ABRASCE, 2008). Este fato fez com a concorrência no setor sofresse um considerável aumento, impondo aos estabelecimentos uma nova realidade, em que a criatividade no desenvolvimento de novas estratégias pode ser fatorchave na permanência no mercado.

Encontraram-se vários artigos sobre o mix de lojas em shopping centers, chamado de tenant mix (BEAN et al., 1998; GERBICH, 1998; BROWN, 1992; SLONGO e MEIRA, 1998; ARAÚJO e RAMOS, 2007; SCHLEMER e PRADO, 2006). Entretanto, não se conseguiu identificar nenhum estudo a respeito do mix de marketing de varejo em estabelecimentos como o de um shopping center. 
Sendo assim, verificaram-se as diferenças na prática de ações dentro do composto mercadológico de varejo entre shoppings, como um todo, de uma localidade específica e como estas práticas se diferenciam da teoria proposta, além das mudanças sofridas no decorrer de sua existência. Para tanto, foi escolhido dois municípios vizinhos, localizados no estado de Santa Catarina, e, para a definição da amostra pesquisada, considerou-se os shopping centers que estão há, no mínimo, cinco anos no mercado. Os resultados obtidos e comentados após a revisão da literatura fornecem subsídios para incrementar o conhecimento a respeito do tema junto a operadores de shoppings e acadêmicos, além de colaborar para as discussões e sugestões para trabalhos futuros.

\section{Referencial teórico}

Quando se faz uma análise de mercado, com o desejo de se implantar um novo negócio, uma indústria de qualquer tipo, sempre surge um aspecto muito importante a ser tratado: como os produtos desta nova indústria serão vendidos? A resposta surge tão rápida como a pergunta: por meio do varejo. Hoje o crescimento do varejo no País e fora dele tem sido muito grande, pois as indústrias contam com o crescimento desse setor para a distribuição de sua produção, bem como para exposição da sua marca junto ao cliente, além de, culturalmente, o que é desenvolvido pelo setor do varejo, de qualquer tipo, é o que o consumidor busca, opções ao alcance dos olhos e das mãos, poder observar os produtos, aproveitar vantagens que possam surgir e afins (PARENTE, 2007; BERNARDINO et al., 2004; BERMAN e EVANS, 2006).

Já que o setor de varejo cresce tanto e um dos pilares de sustentação dele é o marketing bem desenvolvido, é necessário entender o marketing de varejo, uma especialização do marketing que adiciona mais elementos aos estudos de marketing voltados ao varejo. Essa necessidade se aponta como importante, pois este mercado tem algumas peculiaridades interessantes, como o fato de o consumidor ser exposto a, muitas vezes, uma variedade de marcas para o mesmo tipo de produto bastante grande, pelo consumidor ter um contato com outra empresa que não a fabricante, pelo fato de o varejista precisar ter um controle bastante afinado sob suas mercadorias, preços, disponibilidades e afins e por este ser um braço, ainda hoje e durante muito tempo, de sustentação para muitos setores da indústria, pois muitos produtos só podem ser revendidos por meio de varejistas (BERNARDINO et al., 2004; CONSTANTINIDES, 2006).

As necessidades de estudos aprofundados de marketing para o varejo vão além da "simples" relação entre consumidores e revendedores. Há também a preocupação com a expansão dos negócios varejistas dentro de um mesmo país ou para outros países, como destacado por Khanna e Palepu (2006), pois há necessidade de se atentar para diversos fatores que podem influenciar o bom andamento dos negócios, como aspectos culturais, aspectos sobre a distribuição dos produtos, mão de obra e, mesmo, negociações com fornecedores e bancos para financiamentos; para a expansão, ainda há também a preocupação com a rentabilidade de mercados e a diminuição da margem de contribuição de alguns produtos, provocada pela grande competitividade existente, como afirmam Bernardino et al. (2004).

Nesse aspecto, entra também a necessidade de segmentação de mercado ou um conhecimento maior do mercado atendido e estratégias que permitam localizar corretamente seus consumidores em uma loja de varejo e abordar o público de forma correta, sem causar impactos desnecessários. Ou seja, o micro-marketing, trazido por Ziliani (2000), corrobora as ideias de Parente e Kato (2001) quando retratam a área de influência que alguns varejos têm, no sentido de qual o público está ao redor dessas lojas e, ainda, a necessidade de 
ferramentas e estratégias competitivas que tragam o cliente para dentro das lojas, como afirma Balasubramanian (1998).

No Brasil não existem grandes category killers, como se verifica nos Estados Unidos, dando lugar a outros tipos de grandes espaços disponíveis para o varejo, como hipermercados, supermercados e shopping centers (PARENTE, 2007).

Os estudos do marketing de varejo se fazem ainda necessários por algumas peculiaridades encontradas nesse setor: o ticket médio de cada consumidor é muito menor que na indústria; há um número muito maior de compras feitas por impulso e as lojas são muito populares, mesmo em mercados nos quais as vendas por comércio eletrônico são fortes (BERMAN e EVANS, 2006).

Pelas transformações que o mercado sofre, pela evolução do marketing de varejo e do varejo em si como uma das ferramentas mais importantes para a indústria colocar no mercado seus produtos e pelas transformações nas exigências dos consumidores, o modelo convencionalmente utilizado de composto mercadológico dos 4 P's já não contempla tudo que é necessário para o desenvolvimento de uma estratégia. Sendo assim, incluem-se mais 2 $\mathrm{P} ` s$, que permitem uma maior abrangência do composto e maior conhecimento acerca das estratégias disponíveis. (BERNARDINO et al., 2004; CONSTANTINIDES, 2006; PARENTE e BRITO, 2006).

Apresenta-se, a seguir, o objeto de estudo, que é shopping center, e cada elemento do composto de marketing de varejo: preço, produto, praça, promoção, apresentação física da loja e pessoal.

\subsection{Shopping Centers}

A necessidade de tornar a experiência de compra para os consumidores o mais confortável possível e a exigência dos consumidores de obterem maior conforto, estacionamento adequado e poderem encontrar tudo que procuram em um único local podem ter sido os motivos para o surgimento de shopping centers (PRATT e PRATT, 1960).

De acordo com Pratt e Pratt (1960), no início dos anos sessenta, nos Estados Unidos, começaram a surgir, com maior força, os grandes centros de compra - ou shopping centers devido às exigências citadas anteriormente e ao fato de pequenas lojas de varejo precisarem de um local para se estabelecer, que fosse mais facilmente adquirido e que permitisse a abordagem de diferentes públicos. Berman e Evans (2006) consideram, ainda, a possibilidade que esses centros têm de agrupar diversas marcas do mesmo segmento.

A função de um shopping center é a criação de um espaço que facilite, para o consumidor, o encontro de diversos tipos de produtos em um único lugar, divididos entre muitas lojas do mesmo ramo e, para os lojistas, a concentração com outros da mesma área, o que, por um lado, pode aumentar a competição, mas, por outro, permite a concentração em um único lugar e em um ponto, ao menos virtualmente, bem localizado, pois, na grande maioria das vezes, os shopping são construídos em locais estratégicos; os shopping centers constituem-se em um aliado aos pequenos e médios lojistas, pois permite um maior alcance de público e, ainda, a presença de grandes marcas de varejo ao seu redor, atraindo mais clientes (PARENTE, 2007; BERNARDINO, 2004).

Os shopping centers são, ainda, "ferramentas" de transformação social e local, pois desde o momento em que são anunciados até o momento que ficam prontos - e também durante o funcionamento -, causam furor na população, provocam mudanças no consumo 
local, atraem os consumidores que vivem ao seu redor e impactam no funcionamento de novos negócios que podem ocorrer na cidade onde o shopping está instalado (PRATT e PRATT, 1960).

A transformação pela qual a população das proximidades de um shopping center passa são bastante notáveis e significantes. Centros de compras desse tipo atraem, muitas vezes, turistas para o local ou mesmo moradores que buscam maior conforto para realização de suas compras. Por vezes, são os locais preferidos para realização de compras sazonais, como compras para o Natal (PARENTE, 2007; PRATT e PRATT, 1960; BERNARDINO et al., 2004; BERMAN e EVANS, 2006). É possível que, no Brasil, os shopping centers tenham funcionado melhor que as lojas de departamentos, pois o brasileiro esteve sempre em busca de melhores preços, de conforto para realização de suas compras e de locais onde pudesse também se alimentar e divertir enquanto passeia com a família.

Uma das mais importantes decisões no momento da instalação de um shopping center é, para Parente (2007) e Berman e Evans (2006), a sua localização. De posse dos objetivos do centro de compras, do tipo de lojas que irá permitir se instalarem, dos consumidores que deseja atrair e das possibilidades que o centro de compras irá possuir, planeja-se a localização, pensando na população das redondezas, que, segundo estes autores, pode determinar uma grande porção do faturamento desses centros. Ainda para Berman e Evans (2006), os shoppings podem representar, para os pequenos e médios varejistas, uma maior visibilidade de sua marca e procura por seus produtos, bem como um posicionamento mais elitizado no mercado, mesmo que o shopping esteja focando uma categoria social mais baixa.

Um dos grandes detalhes de um shopping center é a importância de uma gestão bastante acirrada e que procure desenvolver a marca do shopping. Um shopping center precisa ser analisado constantemente por sua gestão para verificar se as lojas que ali se encontram estão seguindo as regras preestabelecidas; se as lojas estão dentro dos padrões esperados, se atraem o público que o shopping espera e se o público está de acordo com o que é praticado pelos seus varejistas (PARENTE 2007; PRATT e PRATT, 1960; BERMAN e EVANS, 2006).

A população brasileira pareceu se adaptar melhor aos shopping centers por se sentir mais valorizada ao realizar suas compras num centro de compras e por achar mais justa a política de preços. O que ocorre, por vezes, é que a política de preços de alguma loja dentro de shoppings chega a conflitar com os preços da mesma marca em lojas fora dos centros de compras, o que pode causar desconforto aos consumidores e problemas aos gestores desses grandes centros. Com base na necessidade que a população sente de preços justos e de sortimento de produtos, é que os shoppings têm seu sucesso. Vale destacar alguns tipos de shoppings observados no Brasil: shopping regional, shopping comunitário, shopping de vizinhança, shopping especializado, outlet center e festival center (PARENTE 2007).

Percebe-se que o brasileiro tem bastante atração por shoppings centers e que esses centros, apesar de, muitas vezes, intencionalmente o fazerem, não conseguem determinar um tipo de classe específica que o frequenta. Talvez os reais compradores sejam os que têm maiores posses, mas percebe-se também que estes são frequentados por classes de menor poder aquisitivo, fato que não ocorria há alguns anos. Isso pode representar uma mudança no comportamento dos consumidores. Resta saber se os shoppings centers acompanharão esta modificação.

\subsection{Preço}

A tomada de decisão acerca do preço para o varejo constitui-se em uma decisão extremamente importante e que pode, por vezes, carregar as outras decisões consigo, pois 
o preço é uma comunicação de valor, e não necessariamente dos custos e, por meio dele, podem-se estabelecer as características de um varejo específico, do público-alvo e mesmo de seus objetivos mais globais, bem como, dependendo dos concorrentes, é uma das decisões mais difíceis de ser tomada (BERMAN e EVANS, 2006; BERNARDINO et al., 2004; PARENTE e BRITO, 2006; PARENTE, 2007).

Para Berman e Evans (2006), o varejista tem três possibilidades de estratégia para estabelecimento de seus preços: a) orientação para descontos - utiliza-se sempre de preços mais baixos para alta competitividade, muitas vezes diminuindo sua margem de lucro; $b$ ) preços como os do mercado - os preços são sempre tomados pela média do mercado, dificultando um possível aumento para maior margem; c) orientação de preços no topo - os preços, neste caso, visam a um público com maior poder aquisitivo, porém menor em número, e margens maiores. Apesar de essas estratégias serem válidas, é verdade que, como afirma Das Gupta (2007), está cada vez mais difícil competir com preços, principalmente em mercados mais bem estabelecidos, pois a concorrência pelo dinheiro do cliente é cada vez mais acirrada, bem como pode, numa tentativa de concorrência, desviar o varejo do seu público-alvo, como afirma Radder (1996).

Há ainda que se destacar a recomendação de Berry (2001), que lembra que os preços devem ser estabelecidos da forma mais justa, e não necessariamente mais baixos (excluindo-se aqui o caso dos grandes varejistas de descontos), para que o consumidor não se sinta lesado, o que também é destacado por Cataluña (2004), ao tratar da discriminação de preços que pode ocorrer para um mesmo produto, dependendo do local onde ele é vendido, o que demonstra a orientação de público-alvo daquela loja varejista e pode representar danos aos praticantes de preços discriminadores. Um destaque importante é a relação que pode existir, para os consumidores, dos preços com a qualidade dos produtos, tornando-se uma decisão global de suma importância para o estratagema do varejo, como Wheatley e Chiu (1977) afirmam.

\subsection{Produto}

A escolha e definição do mix de produtos pode ser o grande momento no qual o varejista vai, após a definição de sua localização, posicionar-se no mercado. O mix de produtos e a variedade deste podem determinar o real atendimento da missão e visão definidas no planejamento estratégico do varejista, pois erros, nesse momento, podem colocá-lo em uma posição não desejada. (PARENTE, 2007; BERNARDINO et al., 2004).

Uma peculiaridade do varejo, que se verifica bastante em shopping centers, é a necessidade de sortimento de produtos, ainda que da mesma categoria, como afirmam Simonson (1999) e Sloot et al. (2006), pois os consumidores são, por natureza, indecisos e, muitas vezes, a disponibilidade de apenas uma marca ou um tipo de produto da mesma categoria levam o consumidor a achar que a qualidade daquele local de varejo não é tão boa, destaque de Wheatley e Chiu (1977), havendo necessidade de um mínimo de variedade para que o consumidor possa escolher e não trocar de loja, pois aquela não oferece escolha, o que leva o varejista a uma importante tomada de decisão no que tange o quão variado será o seu mix de produtos, já que uma variedade grande demais pode causar prejuízos também.

O mix de produtos exige algumas considerações bastante específicas e acertadas, para que se evite a mudança posterior para um mix menor, o que pode também causar um impacto ruim para o consumidor. Sugere-se que as considerações de produtos envolvam os seguintes fatores: demográfico, psicográfico, social, comportamental, loja, comércio eletrônico, vendas 
externas, formato varejista, sazonalidade e oferta personalizada (BERNARDINO et al., 2004; SLOOT et al., 2006; WHEATLEY e CHIU, 1977; DAS GUPTA, 2007).

\subsection{Praça}

A localização do varejo pode ser uma das mais importantes definições do mix, pois, no caso especial do varejo, a mudança é quase impossível, tratando-se de shopping, por exemplo, isso vai representar um maior ou menor interesse da indústria e das marcas no varejo, bem como a atratividade que ele terá para os consumidores (PARENTE e KATO, 2001; PARENTE, 2007; GHOSH e CRAIG, 1983).

Decisões de localização envolvem muitos fatores, como a disponibilidade para investimentos, a análise do público-alvo, um comprometimento de longo prazo, a análise da região na qual se pretende implantar o varejo, o que pode ser um dos fatores mais determinantes para a construção de um shopping, pois disso irá depender que tipo de loja irá ali se estabelecer, qual será o público mais frequente e afins (BERMAN e EVANS, 2006; GHOSH e CRAIG, 1983; RADDER, 1996).

A escolha do local da loja também influencia no tamanho desta loja, na possibilidade de futuras expansões, se necessário for, na possibilidade de redução de custos logísticos, na conveniência para os consumidores e na definição de que tipo de formato varejista pode ser adotado, pois, muitas vezes, no caso de pequenos e médios varejos, o local escolhido é um terreno preexistente à ideia do varejo, ou mesmo um terreno oferecido pelo governo com algumas vantagens tributárias (RADDER, 1996; BERMAN e EVANS, 2006; PARENTE, 2007).

\subsection{Promoção}

Promoção ou comunicação para o varejo é uma ação bastante peculiar e pode determinar a procura dos consumidores pelo local. Diferentemente da indústria, no varejo a promoção envolve as questões de local onde se encontra e, muitas vezes, é baseada em promoção de vendas, pois os varejistas acreditam que mais pessoas sejam atraídas em momentos de promoção de preços (BERMAN e EVANS, 2006; DAS GUPTA, 2007; BERNARDINO et al., 2004).

Segundo Parente (2007), a promoção pode ser norteada observando-se três tipos de comunicação promocional: informativo, persuasivo e de reforço. Para D'Souza e Allaway (1995), a decisão deve ser tomada pensando-se no objetivo real e em como a mídia afetará o varejo, sem pensar nos gastos que serão feitos com isso e, muitas vezes, é necessário que o reforço e a persuasão sejam bastante utilizados, isto porque, como afirmam Das Gupta (2007) e Berman e Evans (2004), o varejo, necessariamente, comunica-se diferentemente da indústria e precisa ter como objetivos o aumento das vendas de curto prazo, o aumento de visitações dos consumidores ao local, o desenvolvimento da marca do varejo (no caso de shoppings ou grandes mercados), as informações a respeito de características exclusivas e a facilitação do trabalho do pessoal de vendas.

\subsection{Apresentação física da loja}

Um dos P's adicionais ao modelo do composto de marketing básico é a apresentação física da loja ou presentation. Destaca-se a aparência da loja de varejo, pois ela deve atrair o 
consumidor, fazendo, por vezes, um papel de promoção e comunicação, mas, além disso, atender à necessidade imediata do consumidor de se sentir bem no local de compra; envolve decisões de disposição interna da loja, bem como de fachada, no caso de shopping centers, da disposição das lojas, da decoração e mesmo do público que irá ali frequentar (PARENTE, 2007; BERNARDINO et al., 2004).

A apresentação da loja pode tornar o tempo do consumidor e o seu momento no interior do varejo mais agradável e, inclusive, estimular a compra, mesmo a feita por impulso. O envolvimento do consumidor com o local pode estimular processos de recompra; a utilização de música e cheiros estimula os sentidos e a emoção do consumidor, fazendo-o relembrar momentos que podem influenciar positivamente em suas decisões. Tornar os momentos do cliente prazerosos no interior de um varejo é o aspecto mais importante que o item apresentação física busca para o composto, sendo que, usando os aspectos inerentes ao consumidor corretamente, pode-se estimular a venda de itens por outros itens, utilizando o espaço físico e a proximidade de categorias de itens, bem como, se as decisões forem equivocadas, o ambiente pode se tornar agressivo para o consumidor e ter o efeito contrário, representando o sucesso ou fracasso do local. Esta decisão não pode ser equivocada, pois, como a localização, tem alta inflexibilidade quando se trata de decoração, cores, layout e afins, que podem ser itens fixos (KALTCHEVA e WEITZ, 2006; WARD et al., 2003; BERNARDINO et al., 2004; PARENTE, 2007; GREWAL et al., 2003).

\subsection{Pessoal}

O P referente às pessoas é parte integrante do composto de marketing do varejo, pois todo o varejo que possui loja física, por natureza, também presta serviços, em menor ou maior escala. Os serviços são prestados por pessoas, e a combinação de ótimos produtos, preços, uma boa localização, comunicação e aparência física, mesmo que feita de forma ótima, pode ser derrotada por um atendimento ruim, pois é nesse momento que o consumidor se vê diante de um igual e procura estabelecer uma relação de empatia (BERNARDINO et al., 2004; PARENTE, 2007; DAS GUPTA, 2007).

Decisões acerca de pessoas envolvem recrutamento e seleção, treinamento, vendas, remuneração, itens que podem parecer ser da gestão de pessoas, quando, na verdade, são, mas que, se não considerados no marketing, poderão levar o estabelecimento ao fracasso. Consumidores satisfeitos podem, em determinados momentos, tomar decisões de recompra ou recomendar o local para outras pessoas. Muitas vezes o atendimento pode determinar o desgosto do cliente e, ainda, é um dos itens mais lembrados quando não é bom (SEIDERS et al., 2005; PARENTE, 2007; BERNARDINO et al., 2004).

Para um varejo, a ação de vendas toma uma proporção muito grande, dado que, muitas vezes, o consumidor precisa ser incentivado a consumir, e este incentivo se dá no atendimento pessoal. Para um shopping center, por exemplo, o atendimento inicia-se desde os seguranças até as pessoas contratadas para trabalhar nas lojas, o que pode significar um menor controle sobre o item de pessoas do composto, mas não é impossível definir com os lojistas, por exemplo, uma política de contratação que seja rigorosa para que todos possam envolver-se no processo e tornar a imagem do shopping melhor (PARENTE, 2007; BERNARDINO et al., 2004; DAS GUPTA, 2007; SEIDERS et al., 2005). 


\section{Metodologia}

A definição do método de pesquisa implica na observação e no pensar sobre os objetivos da pesquisa, baseando-se na necessidade de respostas, e também auxilia na montagem e na obtenção do instrumento que permitirá a coleta de dados (OLIVEIRA, 2001).

Uma pesquisa qualitativa permite o aprofundamento do pesquisador acerca do tema estudado e uma maior possibilidade no sentido de busca de informações, bem como permite uma interatividade bastante singular entre o entrevistado e o entrevistador; as Ciências Sociais são baseadas em muitas análises qualitativas e, na maioria das vezes, até que se permita a estruturação de uma teoria e uma possível generalização, faz-se necessária a realização de pesquisas qualitativas que permitam a observância de fatos e fenômenos e também a direção de novas pesquisas (OLIVEIRA, 2001; RICHARDSON, 1999; GODOI et al. , 2006; CRESWELL, 2007).

A escolha do método qualitativo de pesquisa permite, então, que se observem as peculiaridades de cada local a ser pesquisado, bem como das opiniões reais de cada um dos gestores dos shoppings. Como se trata de uma pequena população, também não haveria possibilidade e nem motivo para se realizar uma pesquisa quantitativa, ou seja, a pesquisa qualitativa é praticamente exigida pelo escopo desta pesquisa, além, de como já destacado, permitir um processo de entendimento e de construção do conhecimento baseado em respostas mais profundas e que permitam a análise das informações mais pontuais (BARROS e LEHFELD, 1986; GODOI et al. ,2006; CRESWELL, 2007; OLIVEIRA, 2001; RICHARDSON, 1999).

Como o objetivo desta pesquisa é a análise do composto mercadológico de varejo em dois shopping centers das cidades de Balneário Camboriú e Itajaí, no estado de Santa Catarina, e a análise deste composto foi feita sob a visão dos gestores desses estabelecimentos, a pesquisa qualitativa apresenta-se como a mais indicada para obtenção dos resultados.

Em uma pesquisa acerca do mercado varejista de moda africano, Radder (1996) conduziu, com sucesso, uma pesquisa qualitativa que consistia na entrevista pessoal dos varejistas, que permitisse a ligação do entendimento dos varejistas acerca dos conceitos de marketing e de alguns $\mathrm{P}^{\prime}$ s do composto mercadológico e do que os livros destacavam como sendo importante.

As cidades foram escolhidas pelo papel que representam no estado, sendo as duas cidades vizinhas: uma é considerada polo turístico da região durante o verão e a outra, uma cidade de grande potencial, uma vez que possui um dos portos brasileiros, fato que eleva, anualmente, o número de empresas que lá se instalam, trazendo mais moradores, negócios e, consequentemente, aquecendo a economia local.

Outro fator importante foi o número reduzido de shoppings existentes na região com no mínimo cinco anos de existência (2). Assim sendo, obtiveram-se informações destes dois shoppings disponíveis para a pesquisa. A caracterização de shopping center foi retirada do sítio da Associação Brasileira de Shopping Centers (ABRASCE, 2008), o qual diz que estes devem possuir estacionamento, cinema, praça de alimentação e lojas diversas de produtos e serviços.

Para a aquisição dos dados primários, duas entrevistas foram conduzidas em dois dias específicos: em 29 de maio com o estabelecimento de Balneário Camboriú, e em 05 de junho com o de Itajaí. Os entrevistados foram os gerentes de marketing de cada shopping, os quais atenderam ao pesquisador durante duas horas em média, respondendo a todos os questionamentos realizados, dispondo de muita cordialidade e atenção. As informações foram analisadas por meio de categorização simples das respostas, interpretando-as e comparando-

Rev. Adm. UFSM, Santa Maria, v. 2, n. 2, p. 214-234, maio/ago. 2009 
as com a teoria encontrada e entre si. As entrevistas foram primeiramente gravadas e depois transcritas, resultando em oito páginas de respostas para cada entrevista realizada.

O instrumento de coleta de dados utilizado foi o roteiro de entrevista estruturada. Este foi dividido em sete etapas, e a primeira serviu para contextualizar o shopping pesquisado, buscando informações relacionadas a sua inauguração, as mudanças observadas no mix de lojas e ao público-alvo almejado e alcançado. As etapas seguintes corresponderam ao composto mercadológico de varejo. Cada "P" possuiu de 3 a 4 perguntas, e estas foram baseadas nos respectivos autores:

- Preço (BERMAN e EVANS, 2006; BERRY, 2001; CATALUÑA, 2004);

- Produto ((SIMONSON, 1999; SLOOT et al., 2006);

- Praça (PARENTE e KATO, 2001; GHOSH e CRAIG, 1983);

- Promoção (PARENTE, 2007; D’SOUZA e ALLAWAY, 1995);

- Apresentação (KALTCHEVA e WEITZ, 2006; WARD et al., 2003; GREWAL et al., 2003);

- Pessoas (SEIDERS et al., 2005; PARENTE, 2007).

Os dados secundários foram coletados junto a documentos fornecidos pelos gerentes de cada shopping pesquisado e junto ao sítio da Associação Brasileira de Shopping Centers (ABRASCE). Este último serviu de base para contextualizar o setor em questão, sua evolução e mudanças percebidas no segmento e representatividade na economia nacional.

\subsection{Contextualização do setor de shopping centers no Brasil}

Neste item, são apresentados os dados coletadas junto ao sítio da ABRASCE, com o intuito de disponibilizar informações a respeito do setor pesquisado e apresentar os resultados das entrevistas realizadas com o gerente de marketing de cada shopping pesquisado, comparações entre os estabelecimentos e com a teoria discutida no referencial teórico.

A Tabela 01 mostra a participação dos shopping centers por região no País, apresentando também a área bruta locável de cada uma.

Tabela 01 - Participação por região 2008

\begin{tabular}{l|c|c|l|c}
\multicolumn{1}{c|}{ Regiões } & No. de Shoppings & \% do Total & $\begin{array}{c}\text { Área Bruta } \\
\text { Locável }\end{array}$ & \% do Total \\
\hline Norte & 10 & $2,7 \%$ & 254.559 & $3,1 \%$ \\
\hline Nordeste & 50 & $13,6 \%$ & 1.173 .170 & $14,1 \%$ \\
\hline Centro-Oeste & 33 & $9,0 \%$ & 672.706 & $8,1 \%$ \\
\hline Sudoeste & 202 & $55,0 \%$ & 4.955 .607 & $59,7 \%$ \\
\hline Sul & 72 & $19,6 \%$ & 1.244 .500 & $15,0 \%$ \\
\hline Total & 367 & $100 \%$ & 8.300 .542 & $100 \%$ \\
\hline
\end{tabular}

Fonte: ABRASCE (2008).

Como pode ser observado na Tabela 01, a maior concentração de shopping centers está na Região Sudeste, com 202 estabelecimentos inseridos nesse setor. A Região Sul está em segundo lugar, com 72 estabelecimentos. Percebe-se uma grande disparidade no número de shopping centers quando se verifica cada região separadamente. O maior PIB e a maior 
população do brasileira encontram-se nas duas regiões com a maior quantidade de shoppings, e tais fatos podem acarretar esta concentração.

Tais afirmações podem estar ligadas às ideias de Berman e Evans (2006), os quais afirmam que os shoppings podem representar para os varejistas que ali se inserem uma maior visibilidade de sua marca e procura por seus produtos e serviços. Estando localizados em shoppings, principalmente nas regiões Sudeste e Sul, os lojistas tentam alcançar públicos dos mais variados segmentos e, ainda, conseguem um posicionamento mais elitizado das suas marcas.

A Tabela 02 apresenta as distribuições do número de shopping centers entre os estados das regiões Sudeste e Sul do Brasil.

Tabela 02 - Distribuição de shopping centers e empregos nas regiões Sul e Sudeste em 2008

\begin{tabular}{|c|c|c|c|}
\hline UT & No, de Shoppings & Area Bruta Lecável & Empregos \\
\hline Espirito Santo & 3 & 74.327 & 5.700 \\
\hline Minas Gerais & 27 & 488.391 & 38.000 \\
\hline Rio de Janeiro & 49 & 979.865 & 76,400 \\
\hline Sâo Panto & 123 & $3,413,024$ & 256.000 \\
\hline Parianá & 27 & 502.032 & 38.600 \\
\hline Santa Catarina & 15 & 268.129 & 20.900 \\
\hline Rio Grande do Sal & 30 & 474.339 & 36.000 \\
\hline
\end{tabular}

Fonte: ABRASCE (2008).

Os dados da Tabela 2 demonstram a participação de cada estado das regiões Sudeste e Sul no número de shoppings e na quantidade de empregos por eles gerada. Pratt e Pratt (1960) associam os shopping centers a "ferramentas" de transformação social e local. Tais transformações puderam ser observadas nas localidades onde tais estabelecimentos se encontram, visto a quantidade de empregos e o consequente incremento da economia da região, proporcionadas por suas implementações. 
O Gráfico 1 exibe a evolução do faturamento em shopping centers no Brasil em milhões de reais, de 2000 até o fim de 2008.

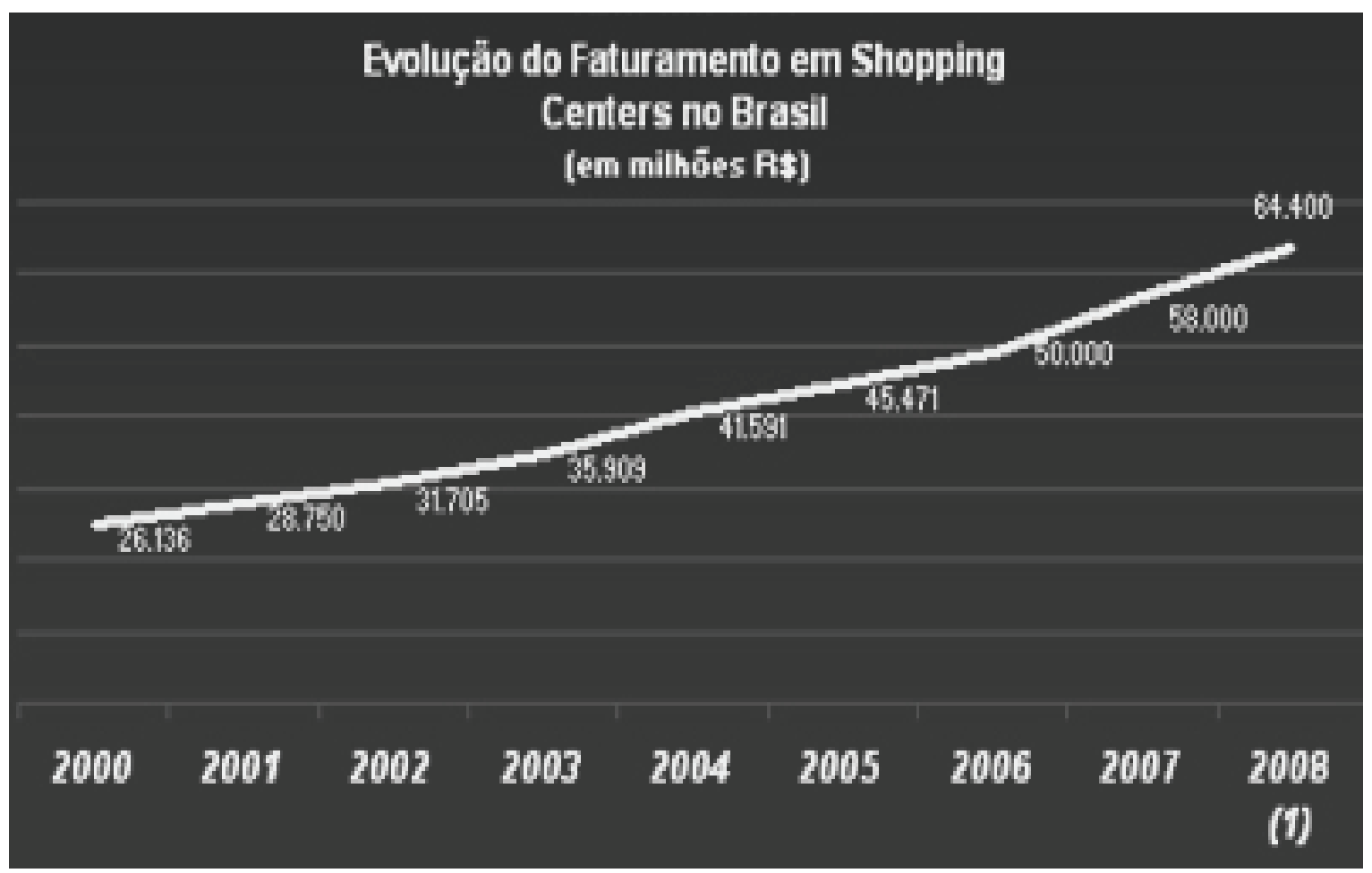

Fonte: ABRASCE (2008).

Gráfico 01 - Evolução do faturamento em shopping centers no Brasil.

Pode-se perceber, de acordo com o Gráfico 01, a evolução constante do faturamento dos marketing centers desde 2000. A estimativa para o ano de 2008 é de 64,4 milhões de reais. Tais dados refletem o bom momento da economia brasileira e o papel exercido pelo varejo. Bernardino et al. (2004) e Constantinides (2006) comentam sobre o crescimento constante do varejo e a necessidade de compreender o marketing nele praticado. Nesse sentido, buscaramse informações junto aos gerentes dos dois shoppings analisados com relação ao composto mercadológico por eles praticado.

\subsection{Análise da entrevista - Itajaí Shopping}

A gerente do Itajaí Shopping, que trabalha desde 2006 na posição de gestora de marketing da organização, único na cidade com estacionamento, cinemas e praça de alimentação, participou da entrevista e foi muito atenciosa e prestativa, fornecendo detalhes importantes para a pesquisa. O Shopping, localizado na cidade de Itajaí, Santa Catarina, foi inaugurado em 17/10/2000, portanto, tem nove anos. Durante esse período, a cidade cresceu, recebeu novos moradores, investimentos estaduais e federal devido ao porto, situado na mesma cidade, o que trouxe mais consumidores para o estabelecimento, que, constantemente, se adapta às novas tendências e hábitos dos clientes que o frequentam. 


\subsubsection{Características gerais}

A sua localização é considerada central, e o shopping foi idealizado depois que a sua estrutura estava pronta. Um grupo da região tinha pensado em um estabelecimento com as características de shopping, entretanto não obtiveram recursos para a sua finalização, e o grupo paranaense resolveu finalizá-lo. O presente estabelecimento possui dois cinemas, cada um com 186 lugares, 350 vagas de estacionamento e 80 lojas que almejam clientes da classe $\mathrm{A}$ à $\mathrm{C}$.

Com relação à distribuição do mix de lojas, foi respondido que, desde a captação de lojas para a inauguração, é realizada uma pesquisa de mercado com o intuito de verificar quantas lojas pertencentes a cada segmento poderiam ser instaladas no shopping. Nos últimos anos, o planejamento inicial do mix de lojas não foi alterado, modificando apenas o local dos corretores, que, atualmente, ficam em Curitiba e comercializam as novas lojas a partir desta cidade. A única mudança ocorrida foi a análise de uma loja que, anteriormente, poderia ser negada. Agora é verificado se a loja pertence a alguma rede e se a sua existência no shopping seria de interesse para o local.

Outro ponto questionado foi a existência de lojas-âncora. As Lojas Americanas estão no shopping desde a sua inauguração, e as lojas Graziottin, uma loja de departamentos que havia neste estabelecimento desde a abertura, faliu e fechou todas as unidades existentes. Sendo assim, existe um espaço que está disponível para locação e que deve ser preenchido por outra âncora. Este local, atualmente, é utilizado para a realização de eventos.

Quando se questionou a respeito do público-alvo almejado e alcançado, foi respondido que a média de pessoas que visitam o shopping em um dia é de mil pessoas. Afirmou-se também que o próprio shopping já seleciona as classes sociais que o frequentam. Percebeu-se, com o passar do tempo, que a classe $C$ passou a comparecer ao shopping com mais frequência, devido ao seu aumento de renda e, consequentemente, de poder aquisitivo. As classes inferiores, de acordo com a gerente, não se sentem bem de comparecer a um shopping, com exceção de eventos específicos, como a inauguração da decoração de Natal. Neste caso, as classes mais baixas vêm ao estabelecimento.

\subsubsection{Preço}

Após as características gerais do shopping, os questionamentos ficaram voltados ao composto do varejo, iniciando-se pelo preço. A primeira questão investigou se o shopping impõe limites aos lojistas e observou-se que os preços são livres, isto é, cada lojista pratica os preços de acordo com as suas necessidades. Foi comentado que, às vezes, uma mesma loja localizada em dois shoppings diferentes, pratica preços diferentes para os mesmos produtos, em razão de os aluguéis também serem de diferentes valores.

Outro ponto pesquisado foi a realização de pesquisas junto aos consumidores para verificar se os preços praticados pelas lojas do shopping estão de acordo com o resto do mercado. Constatou-se que nenhuma pesquisa deste tipo foi aplicada.

Indagou-se também a respeito da percepção do gestor sobre os preços praticados pelo shopping e a qualidade transparecida por ele aos clientes. Foi respondido que, muitas vezes, se vê clientes oriundos de outras regiões frequentando o shopping e que isso se deve ao fato de os preços serem acessíveis, o ambiente aconchegante e livre de engarrafamento. 


\subsubsection{Produto}

Quanto ao item "produto" do composto de varejo, indagou-se sobre a escolha das lojas que são implantadas no shopping. Neste caso, observou-se que há corretores que negociam com os lojistas, sempre respeitando o mix estabelecido na pesquisa previamente realizada, conforme citado anteriormente. Já na praça de alimentação, o bom senso dos lojistas prevalece, visto que eles mesmos acabam não abrindo um determinado restaurante se já existe um similar no mesmo local.

Questionou-se sobre a posição do shopping quanto à exclusividade exigida por algumas lojas, e se a gestora acreditava nessa política. Verificou-se que, no caso do Itajaí Shopping, existem contratos diferenciados. Neste aspecto, a gestora afirmou que cada caso precisa ser analisado, devendo ser bom tanto para o lojista como para o shopping.

\subsubsection{Praça}

Foi comentado a respeito da escolha do local do shopping. Conforme previamente citado, uma empresa havia iniciado as obras, porém não as finalizou e, como o grupo responsável pelo shopping possuía interesse em investir na região, acabou comprando a estrutura. Podese perceber, se comparado a outras estruturas do grupo, que a do Itajaí Shopping está fora do padrão, justamente pelo fato de a construção ter sido iniciada por outra corporação. Com relação ao público alcançado, comentou-se que uma grande parte vem de municípios vizinhos, como Navegantes, Penha, Piçarras, Barra Velha, Luiz Alvez, Balneário Camboriú e Itapema.

Falou-se também que se pretende ampliar o shopping a partir do final de 2009 para a área onde, atualmente, fica o estacionamento descoberto. Além disso, foi citado o fácil acesso ao shopping. Como empecilho, citou-se a proibição de incluir placas de sinalização junto às demais placas alocadas pela prefeitura, fato este que prejudica a chegada de alguns turistas ao local.

\subsubsection{Promoção}

Questionou-se a respeito das promoções desenvolvidas para a atração de consumidores. Nesse aspecto, percebeu-se uma grande preocupação, visto que o shopping possui, em seu calendário, campanhas próprias, sendo elas: Dia da Mulher, Páscoa, Dia das Mães, férias de julho, Dia dos Pais, Dia das Crianças, Natal e verão. São utilizados rádio e jornal na maioria dos casos e, em alguns momentos, também outdoor. Além dessas, utilizam-se, ainda, mídias internas, como elevador e banheiro.

Com relação a promoções de vendas, comentou-se que ocorrem as liquidações de inverno e de verão. A primeira está ligada ao Dia dos Pais e a segunda é realizada especificamente em fevereiro. Há um problema crescente encontrado nas lojas de rede, visto que estas vêm sendo obrigadas a liquidar seus produtos em um período cada vez mais cedo, fato que vem prejudicando o shopping na tentativa de lançar uma liquidação geral.

\subsubsection{Apresentação}

Neste quesito, percebeu-se a preocupação em manter um clima agradável nos corredores e a limpeza de todo o estabelecimento, para que os clientes possam notar a harmonia do conjunto a eles proporcionado. Uma regra comentada, referente à organização do ambiente, foi o de que todas as vitrines devem ser reformuladas após o fechamento do 
shopping. A música é trabalhada tanto para entreter, como para atrair os clientes, e os aromas são trabalhados individualmente e não por todo o shopping.

Os layouts das lojas devem passar pela aprovação do arquiteto do próprio shopping. A preocupação em proporcionar espaços de aconchego também é latente, visto que bancos são espalhados por todo o estabelecimento. Já ocorreu a tentativa de se espalhar puffs e sofás pelas dependências, porém o publico adolescente fez com que a diretoria os retirasse.

\subsubsection{Pessoas}

Os seguranças são próprios do shopping, que oferece treinamento para todos os seus funcionários e também para os lojistas. Os lojistas recebem, periodicamente, um curso de três meses de duração sobre excelência no atendimento, além de palestras sobre a prática de vendas, entre outros.

\subsection{Análise da entrevista - Atlântico Shopping}

O gerente do Atlântico Shopping, que trabalha no local desde 2003 e como gerente de marketing desde 2006, participou da entrevista e forneceu todas as informações requisitadas com muita presteza e atenção. Comentou que o estabelecimento foi inaugurado em 06/12/1997, completando, em 2008, onze anos. Foi o único com características de shopping por quase 10 anos (em novembro de 2007, foi inaugurado o seu principal concorrente direto, o Balneário Camboriú Shopping) e está localizado na região central da cidade. Com a explosão imobiliária sofrida na região, pôde aumentar o número de clientes, que antes se concentrava nos meses de verão, para o restante do ano.

\subsubsection{Características gerais}

O Atlântico Shopping é um dos únicos no Brasil que possui a característica de condomínio. No caso, existem 147 estabelecimentos, entre lojas e quiosques, que têm como segmento-alvo públicos da classe $\mathrm{A}$ à $\mathrm{C}$. Cada ponto desses possui um proprietário. Há um conselho consultivo que decide sobre o mix de lojas. Pretende-se diminuir a quantidade de quiosques, que aproveitam um condomínio mais barato. Outra questão também que foi modificada desde a inauguração foi o mix de lojas existente. No início, todos os segmentos que quiseram se inserir no shopping foram aceitos, com o intuito de preencher todas as lojas disponíveis. Hoje em dia há a preocupação de incluir somente um determinado número de lojas do mesmo segmento no shopping.

Com relação ao público-alvo, percebe-se que houve uma ligeira mudança durante o ano, visto que a população da cidade cresceu. Públicos de cidades vizinhas também frequentam o shopping e, sendo assim, algumas campanhas são realizadas fora da localidade do estabelecimento.

Em virtude de as lojas pertencerem a diversos proprietários, não há uma loja-âncora específica (o shopping considera o próprio cinema uma âncora). Esta questão é prejudicada novamente pelo fato de o estabelecimento ser um condomínio. O gerente citou que há outro shopping, em Londrina, Paraná, com as mesmas características. 


\subsubsection{Preço}

Questionou-se a respeito da pré-definição dos preços por parte do shopping e, mais uma vez, foi comentado da impossibilidade dessa ação devido às especificidades de um shopping condomínio. Também foi indagado sobre a percepção do gestor quanto aos preços praticados e a qualidade oferecida pelo shopping. Neste caso, foi informado que isto sempre foi uma preocupação do estabelecimento e que se acredita que, dentro do possível, o empreendimento pratica preços de acordo com a qualidade que oferece aos consumidores.

\subsubsection{Produto}

Com relação ao produto, foi comentado que existe um conselho consultivo, o qual possui seis integrantes e um síndico, que são eleitos a cada dois anos pelos proprietários das lojas. Estes se reúnem periodicamente e aprovam ou não se os interessados devem entrar no shopping. No caso da praça de alimentação, também existe o bom senso da pessoa interessada em instalar um restaurante lá. Se há concorrentes, opta-se pela não entrada.

Foi informado que, no início, houve a exclusividade exigida por algumas lojas, mas que, atualmente, isso não acontece mais. O shopping trabalha com exposições de carros da Citroen, e esta marca é a única permitida a expor seus produtos. O gestor comentou que cada caso deve ser analisado antes de garantir a exclusividade a alguma loja.

\subsubsection{Praça}

Neste âmbito, o shopping possui uma ótima localização, situado bem no centro da cidade e que, antes da sua construção, o local já era usado pela população como lazer, visto que ali havia um parque. Como público, é alcançado o de Balneário Camboriú e cidades vizinhas. Hoje em dia, o estabelecimento tem sentido a diminuição do público da cidade, já que várias pessoas ainda estão visitando o outro shopping Center, que foi inaugurado na cidade há sete meses.

Observou-se que o shopping não possui local para realizar uma possível expansão, devido à limitação do lugar onde está situado. O acesso também é um pouco prejudicado devido ao anel viário da cidade, que vem sendo modificado e espera-se que incremente a acessibilidade.

\subsubsection{Promoção}

São trabalhadas as datas comemorativas e as parcerias para a prospecção de eventos para atrair clientes. Existe uma verba destinada para este tipo de ação (fundo de promoção) e representa $20 \%$ do condomínio. Foi verificado que, além do conselho consultivo, existe o conselho de lojistas, também eleito a cada dois anos. Estes atendem diretamente ao marketing, fornecendo opiniões e estudando as propostas de novas ações para cada data.

Com relação a liquidações, foi identificado que há certa dificuldade em trabalhar com todas as lojas, visto que os lojistas nem sempre tem o interesse de liquidar seus produtos no mesmo período. Sendo assim, somente algumas lojas participam da liquidação. Comentou-se também que, no último verão, sentiu-se uma queda nas vendas em virtude do novo concorrente, que se instalou na cidade em novembro de 2007. 


\subsubsection{Apresentação}

Informou-se que o shopping muda muito a sua decoração durante o ano, almejando chamar a atenção de clientes e torná-lo um ambiente de compras agradável. Também foi citada a falta de conscientização a respeito da importância da decoração junto aos lojistas.

O estabelecimento também utiliza a música durante o horário de funcionamento, trabalhando com uma rádio da cidade, que muda a programação de acordo com a hora do dia. Quanto à questão do aroma, os condôminos já discutiram, mas ainda não foi implantado. A apresentação da vitrine também é exigida pela administração do shopping, sendo limitada a participação da escolha do layout interno de cada loja. Comentou-se que se pretende instalar, em breve, espaços para vivência do público em geral.

\subsubsection{Pessoas}

Todos os seguranças são funcionários do shopping e há uma escassez de treinamento, não só destes, como também dos funcionários e lojistas. Pretende-se trabalhar mais com os lojistas, identificando quais campanhas incrementaram as vendas, identificando, assim, as mais eficientes, promovendo seminários e palestras motivacionais a respeito do tema.

\subsection{Implicações conceituais e gerenciais}

Após a análise das entrevistas, sugere-se a comparação das ações dos shoppings entre si e com a teoria estudada. Assim, podem-se identificar as mudanças ocorridas com o tempo e as que estão de acordo com a literatura pesquisada 


\begin{tabular}{|c|c|c|c|}
\hline & Teoria & Itajaí Shopping & Atlântico Shopping \\
\hline $\begin{array}{l}\text { Características } \\
\text { gerais }\end{array}$ & $\begin{array}{l}\text { Local de transformação social } \\
\text { e local (PRATT e PRATT, } \\
\text { 1960); } \\
\text { Atraem, muitas vezes, } \\
\text { moradores e turistas para o } \\
\text { local, que buscam maior } \\
\text { conforto para realização de } \\
\text { suas compras (PARENTE, } \\
\text { 2007; BERMAN e EVANS, } \\
\text { 2006). }\end{array}$ & $\begin{array}{l}\text { Shopping empreendedor; } \\
\text { Crescimento do número } \\
\text { de clientes; de público } \\
\text { Média de ano. } \\
\text { constante durante o ano. }\end{array}$ & $\begin{array}{l}\text { Shopping condomínio; } \\
\text { Incremento no número de } \\
\text { clientes durante o ano em } \\
\text { virtude do crescimento da } \\
\text { cidade; } \\
\text { Grande aumento no verão. }\end{array}$ \\
\hline Preço & $\begin{array}{l}\text { Preço é uma comunicação de } \\
\text { valor, e não necessariamente } \\
\text { dos custos, sendo que, por } \\
\text { meio dele, podem-se } \\
\text { estabelecer as características } \\
\text { de um varejo específico, do } \\
\text { público-alvo e mesmo de seus } \\
\text { objetivos mais globais } \\
\text { (BERMAN e EVANS, 2006; } \\
\text { BERNARDINO et al., 2004; } \\
\text { PARENTE e BRITO, 2006; } \\
\text { PARENTE, 2007). }\end{array}$ & $\begin{array}{l}\text { Público de classes sociais } \\
\text { entre A e C; } \\
\text { Boa relação entre a } \\
\text { qualidade oferecida pelo } \\
\text { shopping e preços } \\
\text { praticados. }\end{array}$ & $\begin{array}{l}\text { Público entre as classes A } \\
\text { e C; } \\
\text { Boa relação entre a } \\
\text { qualidade oferecida pelo } \\
\text { shopping e preços } \\
\text { praticados. }\end{array}$ \\
\hline Produto & $\begin{array}{l}\text { Sugere-se que as considerações } \\
\text { de produtos envolvam os } \\
\text { seguintes fatores: demográfico, } \\
\text { psicográfico, } \\
\text { comportamental, } \\
\text { comércio eletrônico, vendas } \\
\text { externas, formato varejista, } \\
\text { oferta } \\
\text { sazonalidade e } \\
\text { personalizada } \\
\text { (BERNARDINO et al., } 2004 \text {; } \\
\begin{array}{l}\text { SLOOT et al., } 2006 ; \\
\text { WHEATLEY e CHIU, } \\
\text { DAS GUPTA, 2007). }\end{array}\end{array}$ & $\begin{array}{l}\begin{array}{l}\text { Diversidade de lojas para } \\
\text { alcançar diferentes }\end{array} \\
\text { segmentos; } \\
\text { Cuidado com o mix de } \\
\text { lojas desde o início, } \\
\text { observando a quantidade } \\
\text { máxima de lojas de um } \\
\text { mesmo segmento. }\end{array}$ & $\begin{array}{l}\begin{array}{l}\text { Diversidade de lojas para } \\
\text { alcançar } \\
\text { diferentes }\end{array} \\
\text { segmentos; } \\
\text { No início, lojas de } \\
\text { qualquer egmento } \\
\text { podiam entrar, sem a } \\
\text { preocupação de extrapolar } \\
\text { o número de lojas de um } \\
\text { mesmo segmento. } \\
\text { Atualmente, existe um } \\
\text { controle no número de } \\
\text { lojas de um mesmo } \\
\text { segmento que pode se } \\
\text { instalar no shopping. }\end{array}$ \\
\hline Praça & $\begin{array}{l}\text { Decisões de localização } \\
\text { envolvem muitos fatores, } \\
\text { como a disponibilidade para } \\
\text { investimentos, a análise do } \\
\text { público-alvo, } \\
\text { comprometimento de longo } \\
\text { prazo, a análise da região na } \\
\text { qual se pretende implantar o } \\
\text { varejo, o que pode ser um dos } \\
\text { fatores mais determinantes } \\
\text { para a construção de um } \\
\text { shopping, pois disso irá } \\
\text { depender que tipos de lojas } \\
\text { irão ali se estabelecer, qual } \\
\text { será o público mais frequente e } \\
\text { afins (BERMAN e EVANS, } \\
\text { 2006; GHOSH e CRAIG, } \\
\text { 1983; RADDER, 1996). }\end{array}$ & $\begin{array}{l}\text { Boa localização; } \\
\text { Possibilidade de expansão } \\
\text { de sua área; } \\
\text { Alcance do público } \\
\text { almejado no início. }\end{array}$ & $\begin{array}{l}\text { Boa localização; } \\
\text { Sem possibilidade de } \\
\text { expansão. } \\
\text { No início, intenção de } \\
\text { atingir o público da } \\
\text { cidade; } \\
\text { Hoje em dia, além do } \\
\text { público da cidade, espera } \\
\text { atingir o público de } \\
\text { cidades vizinhas. }\end{array}$ \\
\hline Promoção & $\begin{array}{l}\text { A promoção envolve bastante } \\
\text { as questões de local onde se } \\
\text { encontra e, muitas vezes, é }\end{array}$ & $\begin{array}{l}\text { Realiza duas liquidações } \\
\text { por ano; } \\
\text { Trabalha com campanhas } \\
\end{array}$ & \begin{tabular}{lrr} 
Realiza duas liquidações \\
por ano, & \multicolumn{2}{c}{ com am a } \\
participação & de apenas
\end{tabular} \\
\hline
\end{tabular}


Podem-se perceber as principais diferenças entre os dois shoppings e como estes trabalham aspectos específicos, discutidos pela teoria. Nesse sentido, ambos os estabelecimentos implementam suas atividades de acordo com o proposto teoricamente. Entretanto, apenas o Atlântico Shopping parece ter necessitado adaptar seu composto de varejo desde a sua inauguração. Tal comportamento reflete as afirmações de Parente (2007), Pratt e Pratt (1960) e Berman e Evans (2006), que consideram a ação da gestão como sendo de extrema importância para a verificação do padrão seguido pelas lojas e se o público está de acordo com o que é praticado pelos seus varejistas.

\section{Considerações finais e sugestões para trabalhos futuros}

O presente trabalho teve como objetivo analisar o composto mercadológico de varejo em dois shoppings centers das cidades de Balneário Camboriú e Itajaí, no estado de Santa Catarina, sob a visão dos gestores de marketing, utilizando-se, para tanto, uma abordagem qualitativa, por meio da aplicação de um roteiro de entrevista semiestruturado.

Os resultados encontrados mostraram que o Itajaí Shopping não alterou seu composto de varejo desde a sua inauguração, o mesmo não acontecendo com o Atlântico Shopping, localizado em Balneário Camboriú. Este, em virtude da entrada de novos concorrentes e em função das mudanças ocorridas com a população da cidade, teve de adaptar as suas estratégias de varejo, modificando seu mix de lojas e implementando novas atividades que não eram praticadas no início.

Os dois shoppings considerados evidenciaram a importância na prática de preços adequados à qualidade oferecida, boa localização, planejamento quanto ao mix de lojas, que podem ser inseridos no estabelecimento, adequada implementação de campanhas promocionais de liquidações e excelente apresentação visual das lojas e do shopping como um todo, proporcionando um ambiente agradável de compras e lazer. Embora o Atlântico Shopping não realize treinamentos periódicos, entende o seu papel e pretende desenvolvê-los em breve.

Como limitações, destacam-se o número limitado de estabelecimentos para a aplicação da pesquisa e a análise de somente um ponto de vista. Se houvesse mais participantes, as generalizações dos dados poderiam acontecer com maior facilidade. Outros participantes do processo, como lojistas e funcionários, poderiam dar seu parecer para ilustrar melhor o caso.

Uma pesquisa possível de ser abordada em trabalhos posteriores é avaliar o efeito da imagem do shopping, nos mesmos moldes de Oppewal e Timmermans (1997). Outra sugestão seria a implementação de uma abordagem quantitativa, com o intuito de verificar as mudanças nos hábitos de compras dos consumidores locais e se estas foram consideradas pelos shoppings no decorrer dos anos. 


\section{Referências}

ARAÚJO, Gustavo P. de; RAMOS, Anatália S. M. Comportamento de compra por impulso em shopping centers: pesquisa com consumidores de Brasília-DF e Natal-RN. In: ENCONTRO ANUAL DA ANPAD, 30., 2007, Rio de Janeiro. Anais... Rio de Janeiro: ANPAD, 2007. p. 1-16. ABRASCE. Associação Brasileira de Shopping Centers. Disponível em: <http://www.abrasce. com.br>. Acesso em: 07 jun. 2008.

BALASUBRAMANIAN, Sridhar. Mail versus mall: a strategic analysis of competition between direct marketers and conventional retailers. Marketing

Science, v. 17, issue 3, p. 181-195, 1998.

BARROS, Aidil J. P. de; LEHFELD, Neide A. de $S$. Fundamentos de metodologia: um guia para a iniciação científica. São Paulo: McGraw-Hill, 1986.

BEAN, James C. et al. Selecting tenants in a shopping mall. Interfaces, v. 18, n. 2, p. 1-9, 1988.

BERMAN, Barry; EVANS, Joel R. Retail management: a strategic approach. 10th ed. Upper Saddle River: Pearson Prentice Hall, 2006.

BERNARDINO, Eliane de C. et al. Marketing de varejo. Rio de Janeiro: FGV, 2004.

BERRY, Leonard L. The old pillars of new retailing. Harvard Business Review, Best Practice, v. 79, issue 4, p. 131-137, Apr. 2001.

BROWN, Stephen. Tenant mix, tenant placement and shopper behaviour in a planned shopping center. Service Industries Journal, v. 12, n. 3, p. 384-403, 1992.

CATALUÑA, Francisco J. R. Price discrimination in retailing. International Journal of Retail \& Distribution Management, v. 32, n. 4, p. 205215, 2004.

CONSTANTINIDES, Efthymios. The marketing mix revisited: towards the 21 st century marketing. Journal of Markerting Management, v. 22, p. 407-438, April 2006.

CRESWELL, John W. Projeto de pesquisa: métodos qualitativo, quantitativo e misto. Porto Alegre: Artmed, 2007.

DAS GUPTA, Devashish. Retailing in India and the role of the marketing mix. European Retail Digest, issue 53, p. 17-20, Spring 2007.

D’SOUZA, Giles; ALLAWAY, Arthur. An empirical investigation of the advertising spending decisions of a multiproduct retailer. Journal of Retailing, New York, v. 71, p. 279296, 1995.

GERBICH, Marcus. Shopping center rentals: an empirical analysis of the retail tenant mix. Journal of Real Estate Research, v. 15, n. 3, p. 283-296, 1998.

GHOSH, Avijit; CRAIG, C. Samuel. Formulating retail location strategy in a changing environment. Journal of Marketing, v. 47, issue 3, p. 56-68, Summer 1983.

GODOI, Christiane K. et al. Pesquisa qualitativa em estudos organizacionais: paradigmas, estratégias e métodos. São Paulo: Saraiva, 2006.

GREWAL, Dhruv et al. The effects of wait expectations and store atmosphere evaluations on patronage intentions in service-intensive retail stores. Journal of Retailing, New York, v. 79, p. 259-268, Winter 2003.

KALTCHEVA, Velitchka D.; WEITZ, Barton A. When should a retailer create an exciting store environment. Journal of Marketing, v. 70, p. 107-118, Jan. 2006.

KHANNA, Tarun; PALEPU, Krishna G. Emerging giants: building world-class companies in developing countries. Harvard Business Review, v. 85, issue 4, p. 60-69, Oct. 2006.

OLIVEIRA, Silvio L. de. Tratado de metodologia científica: projetos de pesquisa, TGI, TCC, monografias, dissertações e teses. São Paulo: Pioneira Thomson Learning, 2001. 
OPPEWAL, Harmen; TIMMERMANS, Harry.

Retailer self-perceived store image and competitive position. International Review of Retail, Distribution \& Consumer Research, v. 7 Issue 1, p. 41-59, Jan. 1997.

PARENTE, Juracy. Varejo no Brasil: gestão e estratégia. São Paulo: Atlas, 2007.

PARENTE, Juracy; BRITO, Luiz A. L. Estratégia de varejo. In: NETO, Arthur R. et al. (Orgs.).

Marketing: estratégia e valor. São Paulo: Saraiva, 2006. p. 159-191.

PARENTE, Juracy; KATO, Heitor T. Área de influência: um estudo no varejo de supermercados. RAE - Revista de Administração de Empresas, São Paulo, v. 41, n. 2, p. 46-53, abr./jun. 2001.

PRATT, Samuel; PRATT, Lois. The impact of some regional shopping centers. Journal of Marketing, v. 25, p. 44-50, Oct. 1960.

RADDER, Laetitia. The marketing practices of independent fashion retailers: evidence from South Africa. Journal of Small Business Management, v. 36, issue 1, p. 78-84, Jan. 1996. RICHARDSON, Roberto J. Pesquisa social: métodos e técnicas. São Paulo: Atlas, 1999.

SCHLEMER, Cris B., PRADO, Paulo H. M.

Surpresa e a experiência de consumo: um estudo em shopping centers. In: ENCONTRO ANUAL

DA ANPAD, 29., Salvador. Anais... Rio de Janeiro, ANPAD, 2006.

SEIDERS, Kathleen et al. Do satisfied customers buy more? Examining moderating influences in a retailing context. Journal of Marketing, v. 69, p. 26-43, Oct. 2005.

SIMONSON, Itamar. The effect of product assortment on buyer preferences. Journal of Retailing, New York, v. 75, issue 3, p. 347-370, Fall 1999.

SLONGO, Luiz A.; MEIRA, Paulo R. De templo de consumo a templo de lazer: O shopping center como provedor de lazer e entretenimento a seus clientes. In: ENCONTRO ANUAL DA ANPAD, 22., Foz do Iguaçu. Anais... Rio de Janeiro: ANPAD, 1998. p. 1-15.
SLOOT, Laurens M. et al. The short-and longterm impact of an assortment reduction on category sales. Journal of Marketing Research, v. XLIII, p. 536-548, Nov. 2006.

WARD, Philippa et al. Ambient smell and the retail environment: relating olfaction research to consumer behavior. Journal of Business and Management, v. 9, n. 3, p. 289-302, Summer 2003.

WHEATLEY, John J.; CHIU, John S. Y. The effects of price, store image, and product and respondent characteristics on perceptions of quality. Journal of Marketing Research, v. XIV, p. 181-186, May 1977.

ZILIANI, Cristina. Retail micro-marketing: strategic advance or gimmick? The International Review of Retail, Distribution and Consumer Research, v. 10, issue 4, p. 355-368, Oct. 2000. 